\title{
Risk of anal incontinence in women with inflammatory bowel diseases after delivery
}

\author{
Kozeluhova $\mathrm{J}^{1}$, Kotyza $\mathrm{J}^{1}$, Balihar $\mathrm{K}^{1}$, Krema $\mathrm{M}^{1}$, Cedikova $\mathrm{M}^{3}$, Karbanova $\mathrm{J}^{2}$, Kalis $\mathrm{V}^{2}$, \\ Janska $\mathrm{E}^{1}$, Matejovic $\mathrm{M}^{1}$
}

1st Department of Internal Medicine, Pilsen University Hospital, Pilsen School of Medicine of the Charles University in Prague, Pilsen, Czech Republic. kozeluhova@fnplzen.cz

\begin{abstract}
AIM: The aim of our prospective study was to evaluate the development of postpartum anal incontinence in patients with inflammatory bowel disease (IBD) compared to healthy women.

MATERIAL AND METHODS: Patients with IBD and healthy controls enrolled in the study from January 1st 2013 to November 30th 2016 and filled in the anal incontinence questionnaire in the beginning of pregnancy and after vaginal delivery. The results were statistically processed using suitable tests.

RESULTS: A total of 57 women were enrolled, 17 (29.8\%) with ulcerative colitis, 23 (40.4\%) with Crohn's disease, and $17(29.8 \%)$ healthy controls. Incidence of postpartum anal incontinence is comparable across all groups; there was no statistically significant difference between the IBD and control groups (Kruskal-Wallis test by ranks with Dunn correction, non-significant). Postpartum anal incontinence was strongly correlated with the extent of perineal injury ( $r=0.80 ; p<0.0001$; Pearson's linear correlation).

CONCLUSIONS: Women with inflammatory bowel disease in remission do not exhibit higher incidence of postpartum anal incontinence (PPAI) compared to healthy controls; the key correlate of PPAl appears to be the extent of obstetric injury, consistently across all study groups. These results suggest that concerns about postpartum anal incontinence development should not be an indication for Caesarean section in IBD patients (Tab. 6, Fig. 1, Ref. 34). Text in PDF www.elis.sk.

KEYWORDS: inflammatory bowel disease, ulcerative colitis, Crohn's disease, pregnancy, childbirth, anal incontinence.
\end{abstract}

List of Abbreviations: AI - Anal incontinence, CD - Crohn's disease, CS - Caesarean section, EAS - External anal sphincter, FI - Fecal incontinence, IAS - Internal anal sphincter, IBD Inflammatory bowel disease, OASIS - Obstetric anal sphincter injury, PPAI - postpartum anal incontinence, SMIS - St. Mark's Incontinence Score, UC - Ulcerative colitis.

\section{Introduction}

Inflammatory bowel disease (IBD) is an idiopathic condition taking the form of either Crohn's disease (CD) or ulcerative

${ }^{1} 1$ st Department of Internal Medicine, Pilsen University Hospital, Pilsen School of Medicine of the Charles University in Prague, Pilsen, Czech Republic, ${ }^{2}$ Department of Obstetrics and Gynecology, Pilsen University Hospital, Pilsen School of Medicine of the Charles University in Prague, Pilsen, Czech Republic, and ${ }^{3}$ Institute of Physiology, Pilsen School of Medicine of the Charles University in Prague, Pilsen, Czech Republic

Address for correspondence: J. Kozeluhova, MD, 1st Department of Internal Medicine, Gastroenterology and Hepatology Section, Pilsen University Hospital, Pilsen School of Medicine of the Charles University in Prague, Pilsen, Czech Republic, 80 Alej svobody, CZ-304 60 Pilsen, Czech Republic.

Phone: +420.603487174 , Fax: +420.377103381

Acknowledgement: This work was supported by Ministry of Health of the Czech Republic grant no. 00669806, part of the "Conceptual Development of Research Institutions" project, awarded to the Pilsen University Hospital, Pilsen, Czech Republic. colitis (UC). It is a chronic bowel disease affecting particularly young people in reproductive age. Young women with IBD are understandably interested in how their primary disease may affect their fertility and course of pregnancy, as well as in the effects of pregnancy on their condition. Common are concerns about the development of the fetus, the method of childbirth, and the possibility of breastfeeding. Even at present, voluntary childlessness based on concerns about pregnancy and childbirth is not uncommon among IBD patients as these are often unfoundedly presented as potentially dangerous for the primary condition $(1,2)$. There is a large number of studies investigating the impact of IBD and related medication on pregnancy and the fetus, as well as the impact of pregnancy and childbirth on the course of IBD (3-7). An open question is childbirth care for IBD patients, especially concerning the risk of development of post-delivery anorectal dysfunction or de novo perianal disease. The impact of the delivery method chosen on sphincter function and perianal complications remains unclear, both in women with pre-existent perianal disease adjuvant to Crohn's, and in women with ulcerative colitis. There are currently no clinically-relevant guidelines for childbirth in women suffering from IBD. The ECCO (European Crohn's and Colitis Organization) guidelines list as an unambiguous gastroenterological indication for Caesarean section (CS) the presence of active perianal disease or active IBD affecting the rectum. Relative indications for elective CS are IPAA (ileal pouch-anal anastomosis) and the presence of ileorectal anastomosis in women who had undergone colectomy (7). 
Tab. 1. Ulcerative colitis activity based on Mayo sub-score.

\begin{tabular}{lccc}
\hline Parameter & \multicolumn{3}{c}{ Points assigned } \\
\cline { 2 - 4 } $\begin{array}{l}\text { Stool Frequency } \\
\text { Rectal Bleeding }\end{array}$ & $\begin{array}{c}\text { Normal number of stools } \\
\text { for patient }\end{array}$ & $\begin{array}{c}1 \text { to } 2 \text { stools per day more } \\
\text { than normal }\end{array}$ & $\begin{array}{c}3 \text { to } 4 \text { stools more than } \\
\text { normal }\end{array}$ \\
\hline $\begin{array}{l}\text { Physician's Global } \\
\text { Assessment }\end{array}$ & No blood seen & $\begin{array}{c}\text { Streaks of blood with stool } \\
\text { less than half the time }\end{array}$ & $\begin{array}{c}\text { Obvious blood with stool } \\
\text { most of the time }\end{array}$ \\
\hline
\end{tabular}

UC remission is defined as a score of $<1$.

Anal incontinence (AI), or fecal incontinence (FI), is defined as the involuntary and repeated leakage, of varying severity and frequency, of fecal material or flatus from the anal canal with a possible impact on the patient's quality of life (8-10). The average incidence of fecal incontinence in the general population is about $8 \%$ (11). In IBD patients, this is higher than in the general population, standing at about $10 \%$; this includes patients currently in the quiescent phase of the disease (10). Questionnaires on AI or FI track the parameters mentioned above, including information on the need to use anti-diarrhea medication and incontinence aids and the presence of an urge to defecate $(12,13)$. In the general population childbirth is one of the most frequent causes of postpartum AI or FI, especially in the case of vaginal birth with injury to the anal sphincter $(10,14-16)$. Statistically significant increases in the incidence of postpartum anal incontinence have been observed in patients who underwent episiotomy or had thirdor fourth-degree injuries from vaginal birth $(9,17,18)$. The risks of development of FI in IBD in patients after vaginal birth have so far been explored only in a small number of studies, with varying results. A large study in the United Kingdom did not show any impact of vaginal delivery on the development of FI in IBD patients (10). Another, smaller study reported different results, finding a statistically significant increase in the risk of FI development in the postpartum period in Crohn's disease patients after vaginal delivery compared to healthy controls (19). Episiotomy should not be performed in IBD patients if possible from an obstetrics point of view, as there is risk of perianal complications, particularly in CD patients. Nonetheless, episiotomy is still preferred to uncontrolled perineal injury in childbirth $(7,20)$. The objective of the prospective study presented in this paper was to determine whether IBD patients have higher incidence of anal incontinence after vaginal delivery compared to healthy controls.

\section{Materials and methods}

The present prospective comparative study investigated the risk of AI development in patients with IBD compared to healthy controls. The host institution's ethics committee approved the study and all enrolled patients have given their informed consent to participation. The study ran from January 1, 2013, and November 30, 2016; during this period, we enrolled all pregnant IBD patients from a tertiary care center; healthy controls were recruited in gynecological clinics and practices throughout the Pilsen and Karlsbad (Karlovy Vary) regions of Czech Republic. The enroll-
Tab. 2. Crohn's disease activity based on Harvey-Bradshaw Index (HBI).

\begin{tabular}{ll}
\hline $\begin{array}{l}\text { General well-being } \\
\text { (previous day) }\end{array}$ & Very well $=0$ \\
& Slightly below par $=1$ \\
& Poor $=2$ \\
& Very poor $=3$ \\
& Terrible $=4$ \\
\hline Abdominal pain & None $=0$ \\
(previous day) & Mild $=1$ \\
& Moderate $=2$ \\
& Severe $=3$ \\
\hline Number of liquid or soft stools per & --------- \\
day (previous day) & None $=0$ \\
\hline Abdominal mass & Dubious $=1$ \\
& Definite $=2$ \\
& Definite and tender $=3$ \\
\hline Complications outside the bowel & None \\
(check any that apply; score one per & Arthralgia \\
item except for first line) & Uveitis \\
& Erythema nodosum \\
& Pyoderma gangrenosum \\
& Anal fissure \\
& Perianal fistula \\
& Perianal abscess \\
\hline
\end{tabular}

CD remission is defined as HBI score $<5$.

ment criteria for the IBD group were: female, aged 18-40, IBD in remission, without recent perianal or rectal disease. Exclusion criteria included active IBD, active perianal disease, ileal pouchanal anastomosis (IPAA), and the presence of ileo- or colostomy. Patients were approached with the offer to be enrolled in the early stages of pregnancy, no later than the 6th week of gestation. Once patients gave their consent, inclusion and exclusion criteria were evaluated and an initial screening to evaluate IBD activity was performed. At this time all participants filled in an entry St. Mark's Anal Incontinence Questionnaire to evaluate their continence before pregnancy. IBD phenotype was determined using the Montreal Classification (chart). Ulcerative colitis activity was evaluated using a partial Mayo Score including the frequency of defecation, scope of bleeding, and examining physician's assessment (Physical Global Assessment, PGA) (Tab. 1). Crohn's disease activity was evaluated using a simple Harvey-Bradshaw Index including the overall condition of the patient, frequency of defecation, presence of abdominal pain, finding of resistance in the abdominal cavity, and presence of complications outside the bowel (Tab. 2). All participants with IBD were screened every 6 
Tab. 3. St. Mark's Fecal Incontinence Score questionnaire.

\begin{tabular}{lll}
\hline 1. After delivery, do you experience involuntary leakage & 0 & never \\
of solid, well-formed stool? & 1 & rarely \\
& 2 & sometimes \\
& 3 & weekly \\
& 4 & daily \\
\hline 2. After delivery, do you experience involuntary leakage & 0 & never \\
of liquid, diarrhea-like stool? & 1 & rarely \\
& 2 & sometimes \\
& 3 & weekly \\
& 4 & daily \\
\hline 3. After delivery, do you observe involuntary flatulence? & 0 & never \\
& 1 & rarely \\
& 2 & sometimes \\
& 3 & weekly \\
& 4 & daily \\
\hline 4. If present, do these problems necessitate changes in & 0 & never \\
your lifestyle? & 1 & rarely \\
& 2 & sometimes \\
& 3 & weekly \\
5. Do you need to use hygiene aids (e.g. pads) for flatu- & 2 & daily \\
lence or stool leaks? & 0 & nes \\
\hline & & \\
& 4 & \\
& &
\end{tabular}

6. Do you need to use anti-diarrhea medication because 2 yes of these issues?

7. Do you suffer from an urge to defecate (i.e., inability 4 yes to postpone defecation for more than 15 minutes)? $\quad 0 \quad$ no

Anal incontinence is defined as a score of 4 points or more. A score of 24 points (maximum) corresponds to total fecal incontinence.

weeks for the duration of their pregnancy to assess their overall condition and potential IBD activity. The delivery method, use of episiotomy, and the presence of any childbirth-related injury were evaluated by the obstetrician performing the delivery and recorded in the delivery record. 6 weeks after delivery, all IBD and healthy patients again filled in a St. Mark's Anal Incontinence Questionnaire, with questions concerning incontinence in the form of flatus or liquid or solid stool, the need to use pads for fecal incontinence, the need to use anti-diarrhea medication, and the presence of an urge to defecate, including information on the frequency of problems and impact on the patient's lifestyle (Tab. 3) (24).
Statistical analysis

Results were statistically evaluated using the analysis of variance (ANOVA) method, Fischer's exact test, and the KruskallWallis test by ranks (post hoc analysis using Bonferroni corrections). The threshold for statistical significance was set at $\mathrm{p}<$ 0.05 . The linear correlation of the St. Mark's Incontinence Score with delivery-related injury was estimated using Pearson's correlation coefficient.

\section{Results}

The total study population between 2013 and 2016 was 57 women, whereof $17(29.8 \%)$ were diagnosed with ulcerative colitis, 23 (40.4\%) with Crohn's disease, and 17 (29.8\%) were healthy and served as the control group. All IBD patients were in remission at the time of enrollment, as evaluated by a partial Mayo Score for the UC group and the Harvey-Bradshaw Index for the CD group. During the follow-up period, one UC patient showed moderate disease activity in the 16th week of gestation; this was addressed by increasing the dosage of mesalazine and the addition of topical corticosteroids to the treatment regimen; remission was re-established by the 21 st week of gestation. The patient remained in UC remission through the end of gestation and post-delivery, allowing her to remain in the study without affecting the validity of results. IBD phenotype was determined using the Montreal Classification for all enrolled patients. In the UC group, 15 out of the total of 17 patients ( $88 \%$ ) had the extensive (E3) form of the disease; the remaining 2 patients $(12 \%)$ in this group had the left-sided (or distal) (E2) form. In the CD group the disease was predominantly ileocecal (14 out of $23 ; 60.8 \%$ ), with the remainder affecting the colon ( 9 out of $23 ; 39.2 \%$ ). Four of the patients whose $\mathrm{CD}$ affected the colon were also diagnosed with perianal disease. 9 out of the total of 40 IBD patients ( $22 \%$ ) had first diagnosis of IBD before the age of 17 (A1), while in the remaining 31 (78\%), IBD had first been diagnosed between the ages of 17 and 40 (A2). All IBD patients in the study had been diagnosed with the disease prior to pregnancy (Chart). The study thus consisted of three groups: a) the Crohn's disease group $(n=23$; mean age $28.5 \pm 3.9)$; b) the ulcerative colitis group $(\mathrm{n}=17$; mean age $30.71 \pm 4.24)$; and c) the volunteer healthy control group $(n=17$;

Tab. 4. Basic postpartum characteristics of study groups - Crohn's disease (CD), ulcerative colitis (UC), healthy controls.

\begin{tabular}{|c|c|c|c|c|c|}
\hline & & $\begin{array}{c}C D \\
(n=23)\end{array}$ & $\begin{array}{c}\mathrm{UC} \\
(\mathrm{n}=17)\end{array}$ & $\begin{array}{l}\text { Control } \\
(\mathrm{n}=17)\end{array}$ & $\begin{array}{c}p \\
\text { value }\end{array}$ \\
\hline Age (mean \pm SD) & & $28.48 \pm 3.93$ & $30.71 \pm 4.24$ & $28.00 \pm 3.93$ & n.s. \\
\hline $\begin{array}{l}\text { Delivery method } \\
n(\%)\end{array}$ & $\begin{array}{l}\text { Vaginal } \\
\text { CS }\end{array}$ & $\begin{array}{l}18(78) \\
5(22)\end{array}$ & $\begin{array}{l}12(71) \\
5(29) *\end{array}$ & $\begin{array}{c}17(100) \\
0(0)\end{array}$ & $\begin{array}{l}\text { n.s. } \\
<0.05\end{array}$ \\
\hline $\begin{array}{l}\text { Obstetric perineal injury } \\
n(\%)\end{array}$ & $\begin{array}{c}\text { None } \\
1^{\text {st }} \text { degree } \\
2^{\text {nd }} \text { degree } \\
3^{\text {rd }} \text { degree } \\
4^{\text {th }} \text { degree }\end{array}$ & $\begin{array}{c}8(35) \\
7(30) \\
1(4) \\
5(22) \\
2(9) \\
\end{array}$ & $\begin{array}{c}9(53) \\
2(12) \\
1(6) \\
3(17) \\
2(12)\end{array}$ & $\begin{array}{c}4(23.5) \\
4(23.5) \\
6(35) \\
2(12) \\
1(6)\end{array}$ & $\begin{array}{l}\text { n.s. } \\
\text { n.s. } \\
\text { n.s. } \\
\text { n.s. } \\
\text { n.s. }\end{array}$ \\
\hline $\begin{array}{l}\text { Episiotomy } \\
n(\%)\end{array}$ & $\begin{array}{l}\text { Yes } \\
\text { No }\end{array}$ & $\begin{array}{c}2(9) \\
21(91)\end{array}$ & $\begin{array}{c}4(24) \\
13(76)\end{array}$ & $\begin{array}{c}4(24) \\
13(76)\end{array}$ & $\begin{array}{l}\text { n.s. } \\
\text { n.s. }\end{array}$ \\
\hline
\end{tabular}

* significance level: $\mathrm{p}<0.05$ compared to healthy controls, evaluated by Fischer's exact test 


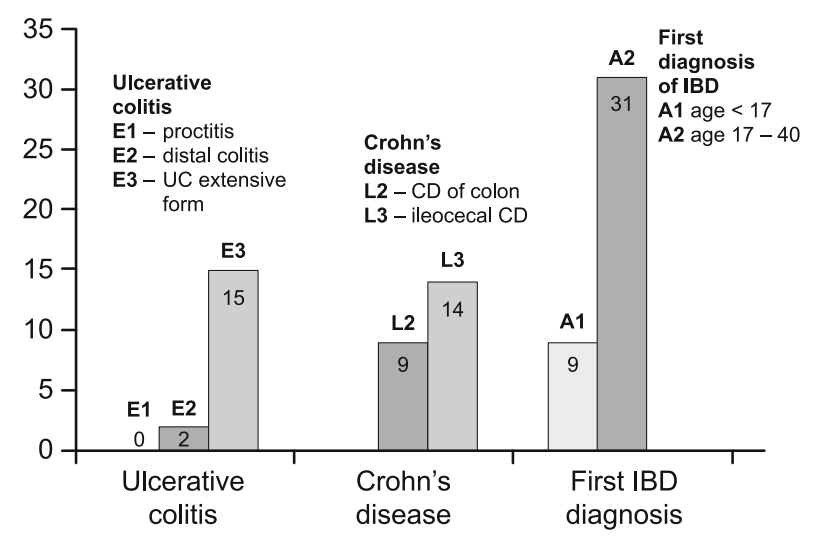

Fig. 1. IBD phenotypes according to the Montreal Classification.

mean age $28.00 \pm 3.93)$. Monitored factors included the type of delivery (vaginal vs. Caesarean section), the degree of perineal injury in childbirth (none to 4th-degree), and the need to perform episiotomy. All patients also filled in the St. Mark's Anal Incontinence Questionnaire at the start of pregnancy (i.e., equivalent to pre-pregnancy state), and again after delivery.

The UC group had significantly higher incidence of Caesarean section births than the healthy control group $(\mathrm{p}<0.05)$; for

Tab. 5. Results of St. Mark's Anal Incontinence questionnaire survey taken at start of pregnancy, study groups: Crohn's disease (CD), ulcerative colitis (UC), healthy controls (results are given as median and interquartile range).

\begin{tabular}{lcccc}
\hline & $\begin{array}{c}\mathrm{CD} \\
(\mathrm{n}=23)\end{array}$ & $\begin{array}{c}\mathrm{UC} \\
(\mathrm{n}=17)\end{array}$ & $\begin{array}{c}\text { Control } \\
(\mathrm{n}=17)\end{array}$ & $\begin{array}{c}\mathrm{p} \\
\text { value }\end{array}$ \\
\hline Involuntary leaks - solid stool & $0(0-0)$ & $0(0-0)$ & $0(0-0)$ & n.s. \\
Involuntary leaks - liquid stool & $0(0-1)$ & $0(0-1)$ & $0(0-0)$ & n.s. \\
Involuntary flatulence & $1(0-1)$ & $1(0-1)$ & $0(0-0)$ & n.s. \\
Lifestyle change & $1(0-1)^{*}$ & $1(0-1)$ & $0(0-0)$ & $<0.05$ \\
Use of hygiene aids & $1(0-1)^{*}$ & $0(0-1)$ & $0(0-0)$ & $<0.05$ \\
Use of antidiarrhetics & $0(0-0)$ & $0(0-0)$ & $0(0-0)$ & n.s. \\
Urge to defecate & $0(0-0)$ & $0(0-0)$ & $0(0-0)$ & n.s. \\
Total - before delivery & $3(0-4)^{*}$ & $2(0-3)$ & $0(0-1)$ & $<0.05$
\end{tabular}

* significance level: $\mathrm{p}<0.05$ compared to healthy controls, evaluated by KruskallWallis non-parametric test

Tab. 6. Results of St. Mark's Anal Incontinence questionnaire survey taken after delivery, study groups: Crohn's disease (CD), ulcerative colitis (UC), healthy controls (results are given as median and interquartile range).

\begin{tabular}{lcccc}
\hline & $\begin{array}{c}\mathrm{CN} \\
(\mathrm{n}=23)\end{array}$ & $\begin{array}{c}\mathrm{UC} \\
(\mathrm{n}=17)\end{array}$ & $\begin{array}{c}\mathrm{ZD} \\
(\mathrm{n}=17)\end{array}$ & $\begin{array}{c}\mathrm{p} \\
\text { value }\end{array}$ \\
\hline Involuntary leaks - solid stool & $0(0-0)$ & $0(0-0)$ & $0(0-0)$ & n.s. \\
Involuntary leaks - liquid stool & $0(0-1)$ & $0(0-1)$ & $1(1-1)$ & n.s. \\
Involuntary flatulence & $1(1-2)$ & $1(1-2)$ & $1(1-2)$ & n.s. \\
Lifestyle change & $1(0-2.5)$ & $1(0-2)$ & $0(0-0)$ & n.s. \\
Use of hygiene aids & $0(0-0)$ & $0(0-2)$ & $0(0-0)$ & n.s. \\
Use of antidiarrhetics & $0(0-0)$ & $0(0-0)$ & $0(0-0)$ & n.s. \\
Urge to defecate & $0(0-0)$ & $0(0-4)$ & $0(0-0)$ & n.s. \\
Total - before delivery & $3(1-7.5)$ & $2(1-11)$ & $2(2-3)$ & n.s. \\
\hline
\end{tabular}

* significance level: $\mathrm{p}<0.05$ compared to healthy controls, evaluated by KruskallWallis non-parametric test the $\mathrm{CD}$ group the significance for this indicator was marginal $(\mathrm{p}=$ 0.06 ). The incidence of postpartum complications and frequency of episiotomy were, on the other hand, not significantly different across the three groups. A summary of these results is given in Table 4 . The assessment of the overall results of the early pregnancy questionnaire survey revealed a statistically significant difference between the CD group and the healthy control $(\mathrm{p}<0.05)$. On an item-by-item basis, the differences were concentrated in questions regarding lifestyle changes and the use of hygiene aids for fecal incontinence. However, there were no statistically significant differences found in the assessment of the post-delivery survey. According to our results, a CD or UC diagnosis has no impact on the risk of development of postpartum anal incontinence (detailed results are shown in Tables 5 and 6). However, our results do indicate a significant correlation of the postpartum St. Mark's Score and the extent of delivery-related injury (Pearson's correlation coefficient $r=0.80 ; p<0.0001$ ).

\section{Discussion}

Crohn's disease and ulcerative colitis commonly affect young, reproductive age people. There is a large number of studies investigating the impact of inflammatory bowel disease and related medication on pregnancy and the fetus, and vice versa, the effects of pregnancy and childbirth on the course of IBD. An open question of considerable clinical significance is the optimal method of delivery in IBD patients with regards to possible sphincter injury and its impact on current and future bowel function (7). One of the unclear issues is the impact of childbirth on the development of postpartum incontinence in IBD patients; there is a need to investigate the effects of vaginal delivery on sphincter function, as well as on the development of perianal complications in patients with pre-existing perianal disease adjuvant to Crohn's and in patients with ulcerative colitis. In the last 20 years, statistics show an increase in the prevalence of Caesarean section births (19, 25-27). Prior studies have demonstrated a higher incidence of Caesarean section births in IBD patients compared to the general population $(28,29)$; this is also seen in our results, where the number of CS births was significantly higher in IBD patients compared to healthy controls. From a gastroenterological standpoint, a clear indication for CS is the presence of active perianal disease or active IBD affecting the rectum; relative indications for elective SC include IPAA (ileal pouch-anal anastomosis) and ileorectal anastomosis in patients who had undergone colectomy for refractory UC. Nonetheless, the decision about the method of delivery should ultimately be made based on obstetric factors.

Anal or fecal incontinence is defined as the involuntary and repeated leakage of fecal material or flatus from the anal canal; severity varies from occasional leaks of fecal material when passing flatus to complete loss of fecal continence. It is a stressful and serious condition with a significant impact on the patient's quality of life, affecting professional, social, and sexual activities (8-10). The incidence of fecal incontinence in the general population is around $8 \%$; however, the distribution is age-asymmetric: In the age group from 20 to 29 , FI prevalence in the general population 
is only about $3 \%$, increasing to $17 \%$ in those aged over 70 (11). An extensive questionnaire survey of IBD patients revealed that up to $74 \%$ of IBD patients experience AI or FI symptoms at least once (10). The incidence of FI in IBD patients is higher than in the general population, standing at about $10 \%$, including patients in the quiescent phase of the disease (10). Our study demonstrated a significantly higher incidence of AI in female Crohn's patients before pregnancy. This may be explained by a colon-affecting CD phenotype combined with perianal disease; although all CD patients in our study were in remission, the localization of the disease may have played a role in the increased incidence of FI. There is currently a lack of consensus in the academic community as to whether the definition of fecal incontinence should also include the involuntary leakage of intestinal gas, or whether it should be limited to the involuntary leakage of liquid and solid stool. However, most authors prefer to exclude intestinal gas from their definition of FI, as flatus leakage is experienced also by a high percentage of healthy individuals. Fecal incontinence surveys track all the mentioned parameters, including the need to take anti-diarrhea medication and use incontinence aids and the presence of an urge to defecate $(12,13)$. As a rule, the term fecal incontinence is used only for the leakage of stool of varying consistency, while the definition of anal incontinence additionally also includes the leakage of intestinal gas from the anal canal (30). Patient surveys have shown that patients consider intestinal gas leaks to be an important sign of incontinence with a significant impact on quality of life that should be included in the definition of FI $(31,32)$. In our study as well, all patients who listed involuntary flatus leaks in the questionnaire also indicated the necessity of lifestyle changes on their part and lower quality of life in general. Many scoring systems for the severity of anal incontinence exist, of varying quality. The currently most commonly-used anal incontinence questionnaire is the Wexner Score; however, in this paper we preferred to use St. Mark's Fecal Incontinence Score, as defined in 1999, to determine the severity of anal incontinence (24). We have chosen this particular method because it surveys not only fecal incontinence in the narrow sense, but also touches on wider issues in anal incontinence with questions on involuntary flatus leakage, the need to use incontinence aids and anti-diarrhea medication, and impacts on patients' quality of life $(13,24)$.

Childbirth is one of the principal causes of anal and fecal incontinence in the general female population, particularly in the case of vaginal delivery with injury to the anal sphincter (obstetric anal sphincter injury, or OASIS). Midline episiotomy for vaginal delivery significantly increases the risk of postpartum FI development compared to vaginal delivery with an intact perineum. Mediolateral episiotomy, even with known sphincter injury (OASIS), appears to be protective against postpartum FI development $(15,33,34)$. The severity of childbirth perineal injury according to perineal rupture classification is defined as: 1st degree - injury to skin and hypodermis of the perineum and the vaginal mucosa; 2 nd degree - with rupture of pelvic diaphragm muscles; 3rd degree - with injury to external anal sphincter (EAS) and internal anal sphincter (IAS); 4th degree - with injury to anal sphincter complex and rectal mucosa $(9,17,34)$. The results of studies on the risk of AI development due to episiotomy and obstetric perineal injury are not completely consistent; however, a recent meta-analysis shows that both episiotomy and 3rd-4th-degree obstetric perineal injury are associated with higher incidence of postpartum AI or FI (9). The risks of FI development in IBD patients have, so far, been only rarely investigated. A large study in the United Kingdom did not show increased risk of FI development in vaginal delivery in IBD patients (10). Different results are presented in a study by Ong, which shows a statistically significant increase in risk of postpartum FI development in CD patients after vaginal delivery compared to healthy controls (19). Episiotomy, if obstetrically possible to avoid, is not recommended for IBD patients due to risk of perianal complications; however, it is still preferred to uncontrolled obstetric perineal injury $(7,20)$. Vaginal delivery in IBD patients is not associated with an increased risk of perianal disease compared to $\operatorname{CS}(7,22,23)$. The study presented in this paper did not show a statistically significant difference in the incidence of obstetric perineal injury and the frequency of episiotomy across our study groups. Our results suggest that a diagnosis of CD or UC does not increase the risk of postpartum AI development; however, we did find a significant positive correlation between the post-delivery St. Mark's Incontinence Score and the extent of perineal injury (Pearson's correlation coefficient $r=0.80 ; p<0.0001$ ).

There is a need for more prospective studies on the relationship of IBD, type of delivery, and development of postpartum AI or FI. These studies should objectively evaluate potential postpartum anorectal dysfunction using manometry or sphincter injury assessment with endoanal ultrasonography or dynamic MRI $(10,19)$.

\section{Conclusion}

The incidence of postpartum anal or fecal incontinence symptoms in patients with IBD is comparable to healthy controls. Postpartum AI or FI incidence is positively correlated with the extent of obstetric injury among IBD patients and the general population. IBD does not appear to be a risk factor for the development of postpartum AI in vaginal delivery; therefore, concerns about the development of postpartum AI should not be a strict indication for Caesarean section in patients with a diagnosis of ulcerative colitis or Crohn's disease. The decision about the method of delivery should, aside from specific indications related directly to IBD, be made primarily on the basis of obstetric factors.

\section{References}

1. Grouin A, Brochard C, Siproudhis L, Leveque J, Bretagne JF, Poulain P et al. Perianal Crohn's disease results in fewer pregnancies but is not exacerbated by vaginal delivery. Dig Liver Dis 2015; 47 (12): 1021-1026.

2. Selinger CP, Ghorayeb J, Madill A. What Factors Might Drive Voluntary Childlessness (VC) in Women with IBD? Does IBD-specific Pregnancy-related Knowledge Matter? J Crohns Colitis 2016.

3. Abhyankar A, Ham M, Moss AC. Meta-analysis: the impact of disease activity at conception on disease activity during pregnancy in patients with inflammatory bowel disease. Aliment Pharmacol Ther 2013; 38 (5): 460-466. 
4. Dignass AU, Hartmann F, Sturm A, Stein J. Management of inflammatory bowel diseases during pregnancy. Dig Dis 2009; 27 (3): 341-346.

5. Dubinsky M,Abraham B, Mahadevan U. Management of the pregnant IBD patient. Inflamm Bowel Dis 2008; 14 (12): 1736-1750.

6. Mahadevan U, Cucchiara S, Hyams JS, Steinwurz F, Nuti F, Travis SP et al. The London Position Statement of the World Congress of Gastroenterology on Biological Therapy for IBD with the European Crohn's and Colitis Organisation: pregnancy and pediatrics. Am J Gastroenterol 2011; 106 (2): 214-223.

7. van der Woude CJ, Ardizzone S, Bengtson MB, Fiorino G, Fraser G, Katsanos K et al. The second European evidenced-based consensus on reproduction and pregnancy in inflammatory bowel disease. J Crohns Colitis 2015; 9 (2): 107-124.

8. Duelund-Jakobsen J, Worsoe J, Lundby L, Christensen P, Krogh K. Management of patients with faecal incontinence. Therap Adv Gastroenterol 2016; 9 (1): 86-97.

9. LaCross A, Groff M, Smaldone A. Obstetric anal sphincter injury and anal incontinence following vaginal birth: a systematic review and metaanalysis. J Midwifery Womens Health 2015; 60 (1): 37-47.

10. Norton C, Dibley LB, Bassett P. Faecal incontinence in inflammatory bowel disease: associations and effect on quality of life. J Crohns Colitis 2013; 7 (8): e302-e311.

11. Ditah I, Devaki P, Luma HN, Ditah C, Njei B, Jaiyeoba C et al. Prevalence, trends, and risk factors for fecal incontinence in United States adults, 2005-2010. Clin Gastroenterol Hepatol 2014; 12 (4): 636-643.

12. Rockwood TH, Church JM, Fleshman JW, Kane RL, Mavrantonis C, Thorson AG et al. Patient and surgeon ranking of the severity of symptoms associated with fecal incontinence: the fecal incontinence severity index. Dis Colon Rectum 1999; 42 (12): 1525-1532.

13. Vaizey CJ, Carapeti E, Cahill JA, Kamm MA. Prospective comparison of faecal incontinence grading systems. Gut 1999; 44 (1): 77-80.

14. Kalis V, Chaloupka P, Turek J, Rokyta Z. Risk factors for 3rd and 4th degree perineal ruptures during delivery. Ceska Gynekol 2005; 70 (1): 30-36.

15. Kalis V, Laine K, de Leeuw JW, Ismail KM, Tincello DG. Classification of episiotomy: towards a standardisation of terminology. BJOG 2012; 119 (5): 522-526.

16. Nichols CM, Ramakrishnan V, Gill EJ, Hurt WG. Anal incontinence in women with and those without pelvic floor disorders. Obstet Gynecol 2005; 106 (6): 1266-1271.

17. Eason E, Labrecque M, Marcoux S, Mondor M. Anal incontinence after childbirth. CMAJ 2002; 166 (3): 326-330.

18. Rusavy Z, Karbanova J, Jansova M, Kalis V. Anal incontinence and fecal urgency following vaginal delivery with episiotomy among primiparous patients. Int J Gynaecol Obstet 2016; 135 (3): 290-294.

19. Ong JP, Edwards GJ, Allison MC. Mode of delivery and risk of fecal incontinence in women with or without inflammatory bowel disease: questionnaire survey. Inflamm Bowel Dis 2007; 13 (11): 1391-1394.
20. Brandt LJ, Estabrook SG, Reinus JF. Results of a survey to evaluate whether vaginal delivery and episiotomy lead to perineal involvement in women with Crohn's disease. Am J Gastroenterol 1995; 90 (11): 1918-1922.

21. Cheng AG, Oxford EC, Sauk J, Nguyen DD, Yajnik V, Friedman $\mathrm{S}$ et al. Impact of mode of delivery on outcomes in patients with perianal Crohn's disease. Inflamm Bowel Dis 2014; 20 (8): 1391-1398.

22. Ilnyckyji A, Blanchard JF, Rawsthorne P, Bernstein CN. Perianal Crohn's disease and pregnancy: role of the mode of delivery. Am J Gastroenterol 1999; 94 (11): 3274-3278.

23. Smink M, Lotgering FK, Albers L, de Jong DJ. Effect of childbirth on the course of Crohn's disease; results from a retrospective cohort study in the Netherlands. BMC Gastroenterol 2011; 11:6.

24. Vaizey CJ. Faecal incontinence: standardizing outcome measures. Colorectal Dis 2014; 16 (3): 156-158.

25. Allen VM, Baskett TF, O'Connell CM. Contribution of select maternal groups to temporal trends in rates of caesarean section. J Obstet Gynaecol Can 2010; 32 (7): 633-641.

26. Ananthakrishnan AN, Cheng A, Cagan A, Cai T, Gainer VS, Shaw SY et al. Mode of childbirth and long-term outcomes in women with inflammatory bowel diseases. Dig Dis Sci 2015; 60 (2): 471-477.

27. Fairley L, Dundas R, Leyland AH. The influence of both individual and area based socioeconomic status on temporal trends in Caesarean sections in Scotland 1980-2000. BMC Public Health 2011; 11: 330.

28. Kornfeld D, Cnattingius S, Ekbom A. Pregnancy outcomes in women with inflammatory bowel disease--a population-based cohort study. Am J Obstet Gynecol 1997; 177 (4): 942-946.

29. Manosa M, Navarro-Llavat M, Marin L, Zabana Y, Cabre E, Domenech E. Fecundity, pregnancy outcomes, and breastfeeding in patients with inflammatory bowel disease: a large cohort survey. Scand J Gastroenterol 2013; 48 (4): 427-432.

30. Norton C, Dibley LB, Hart A, Duncan J, Emmanuel A, Knowles CH et al. Faecal incontinence intervention study (FINS): self-management booklet information with or without nurse support to improve continence in people with inflammatory bowel disease: study protocol for a randomized controlled trial. Trials 2015; 16: 444.

31. Norton NJ. The perspective of the patient. Gastroenterology 2004; 126 (Suppl 1): S175-S179.

32. Norton NJ. Functional Bowel Disorders: A Patient's Perspective. Am J Gastroenterol 2016; 111 (4): 451-452.

33. Kalis V., Rusavy Z., Prka M. Episiotomy. In: Doumouchtsis K.Stergios, editor. Childbirth Trauma. London: Springer-Verlag, 2017, 69-99.

34. Kalis V, Chaloupka P, Turek J, Sucha R, Rokyta Z. Vaginal delivery in primiparas and anal incontinence. Ces Gynekol 2003; 68 (5): 312-320.

Received February 20, 2017. Accepted March 15, 2017. 